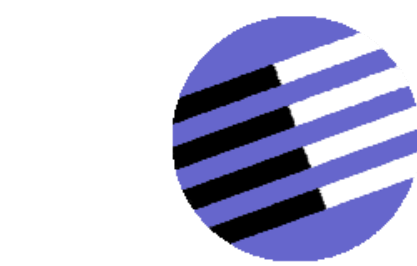

GOVERNANCE AND THE EFFICIENCY

OF ECONOMIC SYSTEMS

GESY

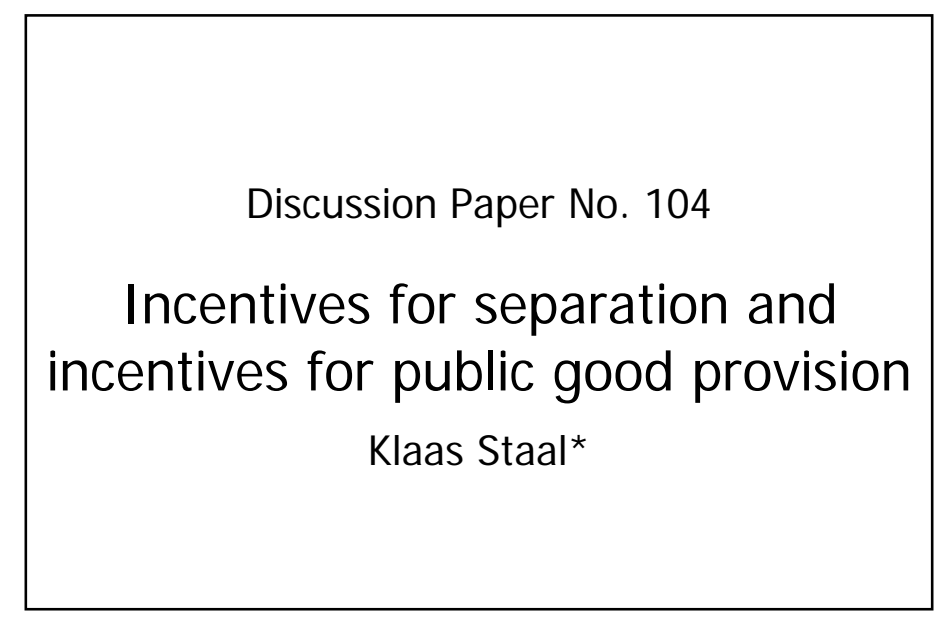

March 2006

*Klaas Staal, Zentrum für Europäische Integrationsforschung ZEI(b), Walter-Flex-Straße 3, 53113 Bonn, Germany and Econometric Institute, Erasmus University Rotterdam, the Netherlands. kstaal@uni-bonn.de

Financial support from the Deutsche Forschungsgemeinschaft through SFB/TR 15 is gratefully acknowledged. 


\title{
Incentives for separation and incentives for public good provision
}

\author{
Klaas Staal*
}

March 30, 2006

\begin{abstract}
In this paper I examine the incentives of regions to unite, to separate and to provide public goods. Separation allows for greater influence over the nature of political decision making while unification allows regions to exploit economies of scale in the provision of public goods. When public good provision is relatively inexpensive, separation occurs since individuals want to assert greater influence, while for intermediate costs of public good provision, separation can be explained by the desires for greater influence as well as for more public goods. Compared with the social optimum, there are excessive incentives for public good provision as well as excessive incentives for separation.
\end{abstract}

Key Words: unification, separation, public good provision, voting.

JEL Numbers: D7, H2, H7.

\footnotetext{
*Zentrum für Europäische Integrationsforschung ZEI(b), Walter-Flex-Straße 3, 53113 Bonn, Germany and Econometric Institute, Erasmus University Rotterdam, the Netherlands. E-mail: kstaal@uni-bonn.de I am grateful to Robert Dur, Sanjeev Goyal, Ewa Mendys and Jo Thori Lind for useful comments and several suggestions that have improved the paper substantially. I would also like to thank participants at presentations in Erasmus (Rotterdam) and at the European Public Choice Society Meeting (Belgirate) for helpful suggestions. Financial support from the Deutsche Forschungsgemeinschaft through SFB/TR 15 is gratefully acknowledged.
} 


\section{Introduction}

In the last 20 years, changes in boundaries attracted attention in the general press as well as in academic research. Some well known examples are the disintegration of the former Soviet Union and Yugoslavia. On the contrary, we have seen the German re-unification and steps to further economic and monetary integration in Europe $^{1}$. Academic researchers have found that majority voting induces excessive incentives for separation -see the discussion of the literature below-. In this paper I develop a framework to study how the incentives for public good provision and the incentives for unification and separation are related.

In the model, I assume that there are two regions which can choose to separate and form two independent countries or to unite and form one country. Under separation, one type of the public good should be provided per country. Individuals in a union, however, have the additional possibility that they may choose to form a federation in which they can mimic something they could achieve under separation, namely the provision of two types of the public good. In a union, the individuals can thus choose to provide one or two types of the public good. If there is disagreement between the two regions in the decision on unification then the two regions will separate. After those decisions, individuals in each political territory choose the type or location of the public good. This determines, for example, where the capitals, the main airports, the universities and other facilities are located. In this spirit, location choices may be interpreted geographically. The model also permits an interpretation in terms of individual preferences more general. In the latter preference interpretation, individuals who are close to each other are assumed to have the same preferred type of public good. Public goods located far from individuals differ more from the preferred type of public good of these individuals than from the preferred type of public good of the individuals who are located in close proximity of the public good. One can for example think of cultural preferences. The people living close to the boundary then have a lower payoff than other individuals since they are far from the public good and since they prefer to have a different type of public good. In both interpretations,

\footnotetext{
${ }^{1}$ See The Times Atlas [1993, Plate 8] for a survey map on border changes and changes in sovereignty since 1945 and Alesina, Spolaore and Wacziarg (2000) for more data on country formation since 1870 .
} 
however, individuals that are close to each other in preferences are also close to each other in preferences.

There is a fixed cost for each type of the public good provided. In case of separation, the individuals in each country have to bear this cost of their public good separately. When there is a union, all individuals bear the costs of the public goods provided, independent of whether two or just one type of the public good is provided. This assumption generates the following trade-off ${ }^{2}$ : separation allows individuals within a small region to exercise greater influence on political decision-making, while unification allows them to exploit economies of scale in the provision of public goods. The incentives for exercising greater influence are called incentives for separation and the exploitation of economies of scale are called incentives for unification. Individuals benefit from the public goods provided. The incentives to increase the amounts provided, either under unification or under separation, are called the incentives for public good provision. The novel insights this approach offers are how the incentives for separation and the incentives for public good provision are connected. So far it is argued in the literature that the inefficiently small size of countries stems from the excessive incentives for separation, while I show that the incentives for public good provision also play a role.

The fixed costs of providing public goods plays an important role in shaping the trade-off voters face. My finding is that for high fixed costs, unification only takes place between relatively similar sized regions. Since the costs of providing public goods are relatively high, individuals will choose to have only one type of the public goods in a union. This result arises out of the different ways in which the political costs of unification compare with the tax advantages. In particular, political costs of unification vary linearly with the size of the other region, while the tax advantages are increasing and (strictly) convex in the size of the other region. This implies that relative to the costs the gains from unification decline for the larger region as the small region becomes smaller. Thus large regions are reluctant to form unions. This is motivated by the incentives for separation as

\footnotetext{
${ }^{2}$ This trade-off as well as some other features are similar to the models presented in Alesina and Spolaore (1997, 2003) and Goyal and Staal (2004). I discuss the relationship of the model with these papers in detail below. Alesina and Wacziarg (1998) present empirical evidence that supports the existence of scale effects in the provision of public goods.
} 
well as by the incentives for public good provision.

I find that for low fixed costs of providing public goods, on the contrary, separation takes place relatively similar sized regions. Since the costs of providing public goods is relatively low, individuals will choose to provide two types of the public good in a union. This result arises out of the same way costs and benefits of unification are compared as the way for relative high values of the fixed costs. Individuals in the large region, however, prefer separation to exert more influence on the type of public goods provided.

I next examine the social welfare implications of decisions made on the basis of these preferences. The main finding is that majority voting leads to excessive separation and excessive provision of public goods. For low fixed costs of providing public goods, it is optimal to provide two types of the public good and we observe excessive incentives for separation. For intermediate fixed costs, it is optimal to provide one type of the public good and we observe excessive incentives for public good provision along with excessive incentives for separation. When public good provision is costly, provision of one type of the public good is optimal as well as the majority voting outcome. The excessive incentives arise out of the way the costs and benefits of unification and public good provision are distributed. The costs in terms of higher per capita tax rates are borne equally by individuals in a region. On the other hand, the benefits from separation and from providing two types of the public good depend on an individual's location. Individuals located close to the boundary between the regions loose relatively more from separation while individuals away from the boundaries gain more from separation. When individuals choose to provide two types of public goods instead of one type, individuals located close to the type of the single public good will loose relatively more than others. The vote of an individual thus generates externalities on other voters; in particular, the analysis shows that voting tends to under-represent the interests of the voters which are losing from separation or from the provision of an additional type of the public good.

This paper is a contribution to the study of the break-up and formation of nations. In recent years, there have been considerable interest in these issues, see e.g. Alesina and Spolaore (1997, 2003), Bolton and Roland (1997) and Goyal 
and Staal (2004). ${ }^{3}$ This political economy work is related the local public good literature and the literature on fiscal federalism ${ }^{4}$. In particular, this paper is closely related to the papers by Alesina and Spolaore (1997, 2003) and Goyal and Staal (2004).

Alesina and Spolaore $(1997,2003)$ study the influence of different factors, such as the level of market integration and democratization, in determining the equilibrium number and sizes of countries. The economic advantages of unification are compared with the political costs of a public good which is located further away in a larger country. In this setting, they find that democratization leads to an inefficiently large number of countries. In the analysis, the boundaries between nations are endogenous and attention is restricted to equal sized countries. The analysis of Goyal and Staal (2004) is based on the same trade-off as the one used be Alesina and Spolaore $(1997,2003)$. Separation allows for greater influence over the nature of political decision making while unification allows the exploitation of economies of scale in the provision of public goods. They study the influence of size, location, the diversity within regions and the role of political institutions in shaping this trade-off. An important assumption in the analysis mentioned above is that in a country only one type of the public good can be provided. In this paper I relax this assumption by allowing individuals in a union to mimic the diversity of public goods provision under separation. Individuals can choose to provide two types of public goods in a union. For high values for the fixed costs of providing public goods the outcomes are identical to the outcomes found by Goyal and Staal (2004), but for low values they did not allow for the provision of two public goods in a union, which I find as the voting outcome. The contribution of this paper is how the incentives for unification, separation and public good provision are related, which is especially interesting in the cases for moderate and low costs of public good provision.

The remainder of this paper is organized as follows. In Section 2 I present the model. Section 3 presents the outcome under majority voting and Section 4 the

\footnotetext{
${ }^{3}$ See Bolton, Roland and Spolaore (1996) for a more extensive review of the early literature.

${ }^{4}$ For the local public good theory, see Austin [1993], Benabou [1993], Bewley [1981], Epple and Romer [1991], Jehiel and Scotchmer [2003], Rubinfeld [1987], Scotchmer [1996], Stahl and Varaiya [1983] and Tiebout [1956]. For literature on fiscal federalism, see Oates [1972], Persson and Tabellini [2000] and Wildasin [1988].
} 
socially optimal outcome. Section 5 concludes with a comparison of the two outcomes and with some more general comments.

\section{The model}

Suppose that different types of public goods can be provided. The range of all possible types of the public good is normalized in the segment $[0,1]$. The type of the public good is denoted by $l$. In addition, assume that the total population has mass one and that individuals from this population are located at ideal points, which indicate their type of the public good. The individuals are uniformly distributed on the segment $[0,1]$. The utility of each individual is decreasing with the distance from his public good to his location (i.e. his ideal point).

Assume that there are two regions with a fixed (exogenous) boundary $\alpha$ and that the two regions can form one or two nations, or "countries". The region located on the left-hand side of $\alpha$ is called region $\mathrm{A}$, while the region on the right-hand side of $\alpha$ is called region $\mathrm{B}$. Without loss of generality, suppose that $0<\alpha<1 / 2$. I assume that there is a fixed cost $F$ per public good. This $F$ includes for example the costs of building airports and hospitals and the costs of having a machinery of government. Every individual has the same exogenous income $y$, and pays the lump-sum tax $t .{ }^{5}$ Now, we can define the utility function for each individual $i$ as follows:

$$
U(i)=g\left(1-a d_{i}\right)+y-t
$$

where $g$ and $a$ are two positive parameters. The parameter $g$ measures the utility of the public good when the preference distance $d_{i}$ is zero and the parameter a measures the loss in utility if the public good is farther away (i.e. when $d_{i}$ increases). The preference distance $d_{i}$ is the difference between the location of individual $i$ and the location of the closest public good in the country where individual $i$ is located. The utility function is thus linear in the preference distance. I assume that $a<1$, which ensures that a higher $g$ increases utility. The marginal utility of the public good located at a distance $d_{i}$ is then equal to $1-a d_{i}$.

\footnotetext{
${ }^{5}$ Proportional taxation with different tax levels across regions is not sustainable when the subject of taxation (e.g. capital or labor) is mobile in a union. In the model with exogenous income levels which are equal across the regions lump-sum taxation is equivalent to proportional taxation. I assume that individual wealth is equal in the two regions.
} 
I look at the incentives for separation and unification under majority voting. Separation occurs if a majority of voters is in favor of separation in at least one region. ${ }^{6}$ In this case one of the public goods has to be located in the small region and the other in the large region. The individuals also have the option to have two public goods in a union. In that case they are free to choose any pair of locations they want. Finally the individuals can choose to have a union with one public good.

Under majority voting, decisions are thus taken in three stages. In the first stage individuals decide how many countries they want to have. If a majority of the individuals in a region prefers to have two nations over one nation the individuals will decide where they want to locate the public goods but if majorities of the individuals in each region prefer to form a union then in the second stage the individuals will decide whether they want to have one or two public goods. In the third stage individuals decide where they want to locate the public good(s).

\section{$3 \quad$ Majority voting}

In this section I examine the outcomes when the decision to form one country with one or two public goods or two countries is taken by majority voting. The decision on the locations of the public goods is studied before the decision on unification and separation.

The decision on the location of the two public goods in one nation: Consider the locations of the public goods when individuals prefer to have a union with two public goods. Define $X=\left\{x_{1}, x_{2}\right\}$ as a pair of two locations for the two public goods and define $\bar{X}=\{1 / 4,3 / 4\}$.

Lemma 3.1. $\bar{X}$ is preferred by a majority in a nation-wide referendum to any other pair of locations for the two public goods.

\footnotetext{
${ }^{6}$ This voting rule is realistic when the central government is too weak or does not want to prevent secession through military means. The disintegration of the former Soviet Union, for example, took place after the central government could not prevent secessions. The past referendum in East Timor and the upcoming referendum in Montenegro are other examples of this procedure.
} 
Proof: Assume, without loss of generality, that $x_{1}<x_{2}$. All the possible deviations from $\bar{X}$ are captured in the following cases:

$\mathcal{I}\left\{0<x_{1}<1 / 4, x_{2}=3 / 4\right\}$ or $\left\{x_{1}=1 / 4,3 / 4<x_{2}<1\right\}$

II $\left\{1 / 4<x_{1}<3 / 4, x_{2}=3 / 4\right\}$ or $\left\{x_{1}=1 / 4,1 / 4<x_{2}<3 / 4\right\}$

III $\left\{0<x_{1}<1 / 4, x_{1}<x_{2}<3 / 4\right\}$ or $\left\{1 / 4<x_{1}<x_{2}, 3 / 4<x_{2}<1\right\}$

$\mathcal{I V}\left\{0<x_{1}<1 / 4,3 / 4<x_{2}<1\right\}$

$\mathcal{V}\left\{1 / 4<x_{1}<x_{2}, x_{1}<x_{2}<3 / 4\right\}$

In all cases, there are two public goods. The tax burden will therefore be the same in all cases. In the decision where to locate the two public goods we can therefore focus on the distance between the location of the public good located closest to an individual and the location of this individual. An individual will prefer a set of locations of two public goods over another set of locations if the distance to the public good is smaller.

Case $\mathcal{I}$ : Let $X_{\mathcal{I}}=\left\{0<x_{1}<1 / 4, x_{2}=3 / 4\right\}$ denote a pair of two locations for the two public goods. Individuals in the interval $(1 / 2,1)$ are indifferent between $\bar{X}$ and $X_{\mathcal{I}}$. The individuals in the interval $\left(0, \frac{x_{1}+1 / 4}{2}\right)$ are in favor of $X_{\mathcal{I}}$, but the individuals in $\left(\frac{x_{1}+1 / 4}{2}, 1 / 2\right)$ are in favor of $\bar{X}$. Since $x_{1}>1 / 4$ there is thus a majority in favor of $\bar{X}$. A similar argument applies to $\left\{x_{1}=1 / 4,3 / 4<x_{2}<1\right\}$. Case $\mathcal{I}$ : : Let $X_{\mathcal{I I}}=\left\{1 / 4<x_{1}<3 / 4, x_{2}=3 / 4\right\}$ denote a pair of two locations for the two public goods. Individuals in the interval $\left(\frac{x_{1}+3 / 4}{2}, 1\right)$ are indifferent between $\bar{X}$ and $X_{\mathcal{I I}}$. The individuals in $\left(0, \frac{1 / 4+x_{1}}{2}\right)$ are in favor of $\bar{X}$, but the individuals in $\left(\frac{1 / 4+x_{1}}{2}, \frac{x_{1}+3 / 4}{2}\right)$ are in favor of $X_{\mathcal{I I}}$. Since $x_{1}>1 / 4$ there is thus a majority in favor of $\bar{X}$. A similar argument applies to $\left\{x_{1}=1 / 4,1 / 4<x_{2}<3 / 4\right\}$.

Case III: Let $X_{\mathcal{I I I}}=\left\{0<x_{1}<1 / 4, x_{1}<x_{2}<3 / 4\right\}$ denote a pair of two locations for the two public goods. Individuals in the interval $\left(\frac{x_{2}+3 / 4}{2}, 1\right)$ are in favor of $\bar{X}$, likewise the individuals in the interval $\left(\frac{x_{1}+1 / 4}{2}, \frac{1 / 4+x_{2}}{2}\right)$ prefer $\bar{X}$ over $X_{\mathcal{I I I}}$. Thus, in total

$$
1-\frac{x_{2}+3 / 4}{2}+\frac{1 / 4+x_{2}}{2}-\frac{x_{1}+1 / 4}{2}=\frac{5 / 4-x_{1}}{2}
$$

This is more than $1 / 2$ since $x_{1}<1 / 4$. Hence, there is a majority in favor of $\bar{X}$. A similar argument applies to $\left\{1 / 4<x_{1}<x_{2}, 3 / 4<x_{2}<1\right\}$.

Case $\mathcal{I V}$ : Let $X_{\mathcal{I V}}=\left\{0<x_{1}<1 / 4,3 / 4<x_{2}<1\right\}$ denote a pair of two locations for the two public goods. Individuals in the interval $\left(\frac{x_{1}+1 / 4}{2}, \frac{3 / 4+x_{2}}{2}\right)$ are in favor of $\bar{X}$. Since $x_{1}<1 / 4$ and $x_{2}>3 / 4$ it follows that a majority prefers $\bar{X}$ over $X_{\mathcal{I V}}$. 
Case $\mathcal{V}$ : Let $X_{\mathcal{V}}=\left\{1 / 4<x_{1}<x_{2}, x_{1}<x_{2}<3 / 4\right\}$ denote a pair of two locations for the two public goods. Individuals in the interval $\left(0, \frac{1 / 4+x_{1}}{2}\right)$ and $\left(\frac{x_{2}+3 / 4}{2}, 1\right)$ are in favor of $\bar{X}$. Since $x_{1}>1 / 4$ and $x_{2}<3 / 4$ it follows that a majority prefers $\bar{X}$ over $X_{\mathcal{V}}$.

It follows from the median-voter theorem that in a union with one public good the public good will be located at $1 / 2$. Likewise in case of two nations the two public goods will be located in the center of each nation, respectively.

The decision to have one or two public goods: Now examine the incentives of a nation to have one or two public goods. If public goods are cheap there will be two public goods, otherwise there will be one public good. This is formally stated in the following lemma.

Lemma 3.2. In a nationwide referendum a majority of the individuals will prefer to have one public good over two public goods if and only if $F>g a / 4$.

Proof: The individuals at $1 / 4$ and $3 / 4$ are the median voters. ${ }^{7}$ Due to the symmetry in the model, it suffices to check the preferences of one of the two. The individual at $1 / 4$ prefers one public good over two public goods if and only if $U_{1 P G}(1 / 4)>U_{2 P G}(1 / 4)$ :

$$
g\left(1-\frac{1}{4} a\right)-F+y>g-2 F+y
$$

Hence, a majority of the voters prefers to have a union with one public good over a union with two public goods when $F>g a / 4$.

Preferences over unification and separation in the small region: First observe that if $\alpha$ is very small then the per capita cost of supporting an independent public good, $F / \alpha$, becomes very large and the individuals in the small region will therefore benefit significantly from unification. Next observe that in a union with two public goods the individuals in the small region will be located closer to the public good than in a union with only one public good. The analysis of these issues is summarized in the following lemma.

\footnotetext{
${ }^{7}$ It is straightforward to check that if the individual at $1 / 4$ prefers a union with two public goods then all voters in the intervals $[0,1 / 4]$ and $[3 / 4,1]$ prefer a union with two public goods and that if the individual at $1 / 4$ prefers a union with one public good then all voters in the interval $[1 / 4,3 / 4]$ prefer a union with one public good.
} 
Lemma 3.3. If $F<g a / 4$ then a majority of the individuals in the small region prefers unification for all $\alpha<4 F / g a$. If $F>$ ga/4 then a majority of the individuals in the small region prefers unification for all $\alpha<2 F / g a$.

Proof: If $F<g a / 4$ then there will be two public goods located at $\{1 / 4,3 / 4\}$ in a union. In the small region the median voter is located at $\alpha / 2$. The median voter will prefer unification over independence if and only if his utility in a union, $U_{2 P G}$, is larger than his utility under separation, $U_{I I}$ :

$$
U_{2 P G}\left(\frac{\alpha}{2}\right)=g\left(1-a\left|\frac{1}{4}-\frac{\alpha}{2}\right|\right)-2 F+y>g-\frac{F}{\alpha}+y=U_{I I}\left(\frac{\alpha}{2}\right)
$$

That is, if $\alpha<4 F / g a$.

If $F>g a / 4$ then there will be one public good located at $1 / 2$ in a union. Moreover, there is a majority in favor of unification in the small region if and only if the median voter $\alpha / 2$ prefers unification:

$$
U_{1 P G}\left(\frac{\alpha}{2}\right)=g\left(1-a\left|\frac{1}{2}-\frac{\alpha}{2}\right|\right)-F+y>g-\frac{F}{\alpha}+y=U_{I I}\left(\frac{\alpha}{2}\right)
$$

That is, if $\alpha<2 F / g a$.

Preferences over unification and separation in the large region: The individuals in the large region also compare the benefit of a lower tax rate with the change in the location of the public good.

Lemma 3.4. If $F<g a / 4$ then a majority of the individuals in the large region prefers unification for all $\alpha<1-4 F / g a$. If $F>$ ga/4 then a majority of the individuals in the large region prefers unification for all $\alpha>1-2 \mathrm{~F} / \mathrm{ga}$.

Proof: First consider the case of $F>g a / 4$. There will be a single public good in case of unification. There is a majority in favor of unification in the large region if the median voter $(1+\alpha) / 2$ prefers unification:

$$
U_{I I}\left(\frac{1+\alpha}{2}\right)=g+y-\frac{F}{1-\alpha}<g\left(1-a \frac{\alpha}{2}\right)+y-F=U_{I}\left(\frac{1+\alpha}{2}\right)
$$

That is, if $\alpha>1-2 F / g a$.

Consider now the case of $F<g a / 4$. In case of unification there will now be two public goods located at $1 / 4$ and $3 / 4$. In this case we cannot apply the median voter theorem directly to determine the voting outcome on a union with 
two public goods versus separation. Instead of looking at the preferences of a median voter I will first look at the preferences of the voters at $(1+\alpha) / 2$ and $3 / 4$. There are four possibilities: $(\mathcal{A})$ both voters prefer separation, $(\mathcal{B})$ both prefer unification, $(\mathcal{C})(1+\alpha) / 2$ prefers unification and $3 / 4$ prefers separation or $(\mathcal{D})(1+\alpha) / 2$ prefers separation and $3 / 4$ prefers unification. The individual at $(1+\alpha) / 2$, however, will always prefer separation over unification since he pays more tax in a union but the public good is located farther away. We therefore do not need to pay attention to the cases $(\mathcal{B})$ and $(\mathcal{C})$ : they are impossible.

A look at Figure 1 shows the following.

In a union utility is decreasing with respect to location for the individuals in $(1 / 4,1 / 2)$ and $(3 / 4,1)$, while for the individuals in $(0,1 / 4)$ and $(1 / 2,3 / 4)$ utility is increasing with respect to location. Analogously, utility under separation is decreasing with respect to location for the individuals in $(\alpha / 2, \alpha)$ and $((1+\alpha) / 2,1)$, while for the individuals in $(0, \alpha / 2)$ and $(\alpha,(1+\alpha) / 2)$ utility is decreasing with respect to location. $3 / 4$ is always larger than $(1+\alpha) / 2$ since $\alpha<1 / 2$. Therefore, if individual 3/4 prefers separation, then all individuals between $(1+\alpha) / 2$ and $3 / 4$ prefer separation (case $\mathcal{A}$ ) as well. Moreover, a majority of the individuals in the large region then prefers separation over unification. The individual at $3 / 4$ prefers separation when his utility under unification, $U_{2 P G}(3 / 4)$, is lower than his utility under separation, $U_{I I}(3 / 4)$

$$
U_{2 P G}(3 / 4)=g-2 F+y<g\left(1-a\left|\frac{3}{4}-\frac{1+\alpha}{2}\right|\right)-\frac{F}{1-\alpha}+y=U_{I I}(3 / 4)
$$

That is, if $\alpha>1-4 F / g a$.

So for $4<F<g a / 4$ and $\alpha>1-4 F / g a$ the individual at $3 / 4$ prefers separation over unification with two public goods and hence a majority of the individuals in the large region prefers separation over unification.

Now take case $\mathcal{D}$. I will show that a majority of the voters in the large region prefers unification in this case. Since utility is continuous with respect to location in a union, there should be some individual between $(1+\alpha) / 2$ and $3 / 4$ who is indifferent between unification and separation. I call this individual $R$. In a union, the utility of the individuals in $(1 / 4,1 / 2)$ is decreasing with respect to location, while under separation utility is increasing with respect to location. I therefore claim that there is an individual who is indifferent between unification 


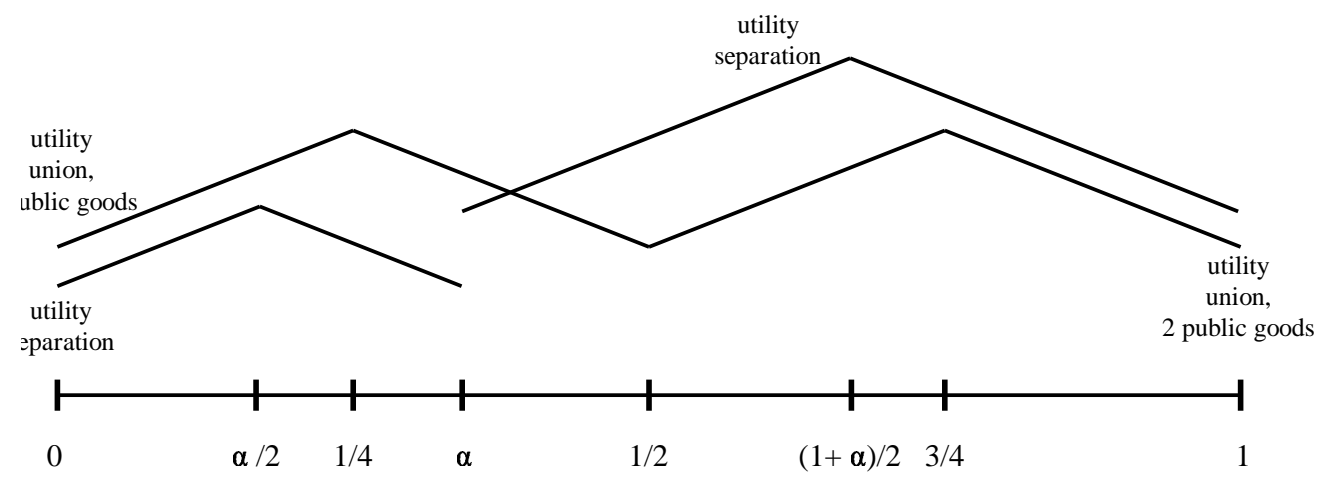

Figure 1a: Case $\mathcal{A}$

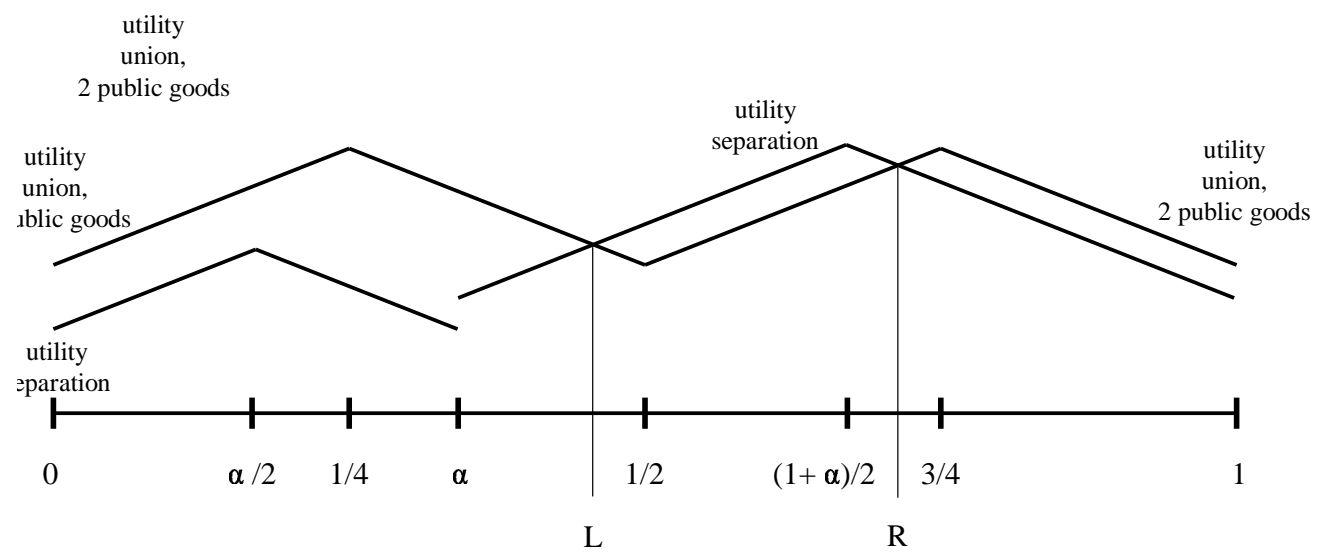

Figure 1b: Case $\mathcal{D}$

Figure 1: Preference of voters. 
and separation. I call this individual $L$. All the individuals located between $L$ and $R$ are in favor of separation.

To find the value of $L$ use the payoff under unification, $U_{2 P G}(L)$, and the payoff under separation, $U_{I I}(L)$, to determine the value of $L$ for which both payoffs are equal.

$$
U_{2 P G}(L)=g\left(1-a\left|\frac{1}{4}-L\right|\right)-2 F+y=g\left(1-a\left|\frac{L-1+\alpha}{2}\right|\right)-\frac{F}{1-\alpha}+y=U_{I I}(L)
$$

This equality is satisfied for

$$
L=\frac{3}{8}-\frac{F}{g a}+\frac{1}{4} \alpha+\frac{F}{2 g a(1-\alpha)}
$$

Note that for $\alpha<1 / 4$ the utility of the individual at $1 / 4$ is higher in a union with two public goods than under separation. This follows from:

$$
U_{2 P G}\left(\frac{1}{4}\right)=g+y-2 F>g\left(1-a\left(\frac{1+\alpha}{2}-\frac{1}{4}\right)\right)+y-\frac{F}{1-\alpha}=U_{I}\left(\frac{1}{4}\right)
$$

that is, if $\alpha<1-4 F / g a$, which is satisfied since for $\alpha>1-4 F / g a$ both individuals would prefer separation. For $\alpha>1 / 4$ the utility of the individual at $\alpha$ is higher in under unification than under separation. This is shown as follows:

$$
\begin{array}{r}
U_{I}(\alpha)=g\left(1-a\left(\alpha-\frac{1}{4}-\alpha\right)\right)+y-2 F> \\
g\left(1-a\left(\frac{1+\alpha}{2}-\alpha\right)\right)+y-\frac{F}{1+\alpha}=U_{2 P G}(\alpha)
\end{array}
$$

that is, if $\alpha<1-4 F / 3 g a$, which is satisfied when $\alpha<1-4 F / g a$. From this it follows that $L$ is indeed in the large region between $\alpha$ and $1 / 2$.

To find the value of $R$ use the payoff under unification, $U_{2 P G}(R)$, and the payoff under separation, $U_{I I}(R)$, to determine the value of $R$ for which both payoffs are equal.

$U_{2 P G}(R)=g\left(1-a\left|\frac{3}{4}-R\right|\right)-2 F+y=g\left(1-a\left|R-\frac{1+\alpha}{2}\right|\right)-\frac{F}{1-\alpha}+y=U_{I I}(R)$

This equality is satisfied for

$$
R=\frac{5}{8}+\frac{F}{g a}+\frac{1}{4} \alpha-\frac{F}{2 g a(1-\alpha)}
$$


The individuals in favor of separation, i.e. the individuals between $L$ and $R$, form a majority if

$$
R-L>\frac{1-\alpha}{2}
$$

This condition can be rewritten as $\alpha>1-4 F / g a$, which is never satisfied since for $\alpha>1-4 F / g a$ case $\mathcal{A}$ would obtain. Hence we see that when $F<g a / 4$ for $\alpha<1-4 F / g a$ we will never observe a majority in favor of separation in the large region.

I summarize the outcomes under majority voting in the following Proposition.

Proposition 3.1. The outcomes under majority voting are given as follows: (a) If $F<g a / 8$ then there is unification if and only if $\alpha \in(0,4 F / g a]$, (b) If $g a / 8<$ $F<g a / 4$ then there is unification if and only if $\alpha \in[1-4 F / g a, 4 F / g a]$, (c) If $g a / 4<F<g a / 2$ then there is unification if and only if $\alpha \in[1-2 F / g a, 1 / 2]$, (d) If $g a / 2<F$ then there is unification for all $\alpha \in[0,1 / 2)$.

These results are illustrated in Figure 2. This figure also shows what the socially optimal outcome is. The socially optimal outcomes are discussed in more detail in Section 4.

For low values of $F(F<g a / 4)$ and relatively large values of $\alpha$ we observe separation. Individuals in the large region have incentives for separation so that they can exert more influence on the type of public good provided, while individuals in the small region always prefer a union with two public goods. For intermediate values of $F(g a / 4<F<g a / 2)$ we observe separation when $\alpha$ is relatively small. Individuals in the large region prefer separation in order to provide relatively more public goods (incentives for public good provision) and to have a greater influence on its type (incentives for separation), while the individuals in the small region always prefer a union with one public good. Finally, when public good provision is costly $(F>g a / 2)$ a majority in both regions prefer a union with one public good. 


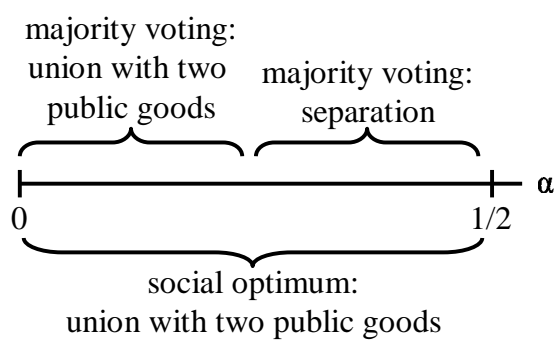

Figure 2a: $\mathrm{F}<\mathrm{ga} / 8$

majority voting

majority voting: union with one

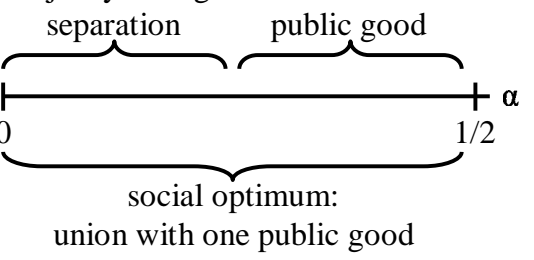

Figure $2 \mathrm{c}: \mathrm{ga} / 4<\mathrm{F}<\mathrm{ga} / 2$

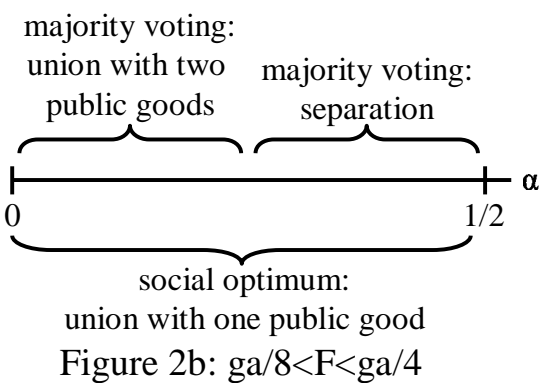

Figure $2 \mathrm{~b}: \mathrm{ga} / 8<\mathrm{F}<\mathrm{ga} / 4$

majority voting:

union with one public good

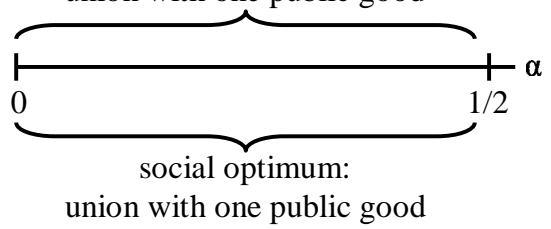

Figure 2d: F>ga/2

Figure 2: Majority voting and social optima. 


\section{Social optimum}

The social optimum: I start by observing that two public goods located at $1 / 4$ and 3/4 induce lower transport costs as compared to two public goods located at $\alpha / 2$ and $(1+\alpha) / 2$. Hence it is socially better to have a union with two public goods as compared to two separate nations.

Lemma 4.1. In all cases a union with two public goods is preferred over two separate nations with public goods in each nation.

Proof: In the social optimum the sum of all individual utilities is maximized. If it is optimal to have a union with two public goods, then it will be socially optimal to choose the location of the public goods and the tax level to maximize the aggregate payoff $U_{2 P G}$ to all individuals in a union with two public goods:

$$
U_{2 P G}=\int_{0}^{1} U_{2 P G}(i) d i=g\left(1-a E\left(d_{i} \mid l\right)\right)+y-E(t)
$$

where $E\left(d_{i} \mid l\right)$ and $E(t)$ are, respectively, the average distance to the public good closest to individual $i$ given the locations of the two public goods and $E(t)$ the lump sum tax level in the nation. In order to minimize $E\left(d_{i}\right)$ it is socially optimal to locate the two public goods at $1 / 4$ and $3 / 4$. $E\left(d_{i} \mid l\right)$ will then be $1 / 8$. Since there are two public goods, $E(t)$ will be $2 F$.

If it is optimal to have two separate nations with two public goods then it will be socially optimal to choose the locations of the public goods and the tax levels to maximize the aggregate payoff $U_{I I}$ to all individuals in the two nations:

$$
U_{I I}=\int_{0}^{1} U_{I I}(i) d i=\sum_{x=A, B} s_{x}\left[g\left(1-a E_{x}\left(d_{i} \mid l_{x}\right)\right)+y-E_{x}(t)\right]
$$

where $E_{x}\left(d_{i} \mid l_{x}\right), s_{x}$ and $E_{x}(t)$ are, respectively, the average distance in country $x$ given the location of the public good, the size of country $x$ and the lump sum tax level in country $x$. Since the value of $\alpha$ is exogenously specified, the values of $s_{A}$ and $s_{B}$ are $\alpha$ and $1-\alpha$, respectively. In order to minimize $E_{x}\left(d_{i}\right)$ it is socially optimal to locate the public good in the middle of each country. Hence, $E_{A}\left(d_{i}\right)$, $E_{B}\left(d_{i}\right)$ and $E\left(d_{i}\right)$ are, respectively, $\alpha / 4,(1-\alpha) / 4$ and $1 / 4$. Each country has to finance its own public good, therefore $E_{A}(t), E_{B}(t)$ and $E(t)$ are, respectively, $F / \alpha, F /(1-\alpha)$ and $F$. 
Hence, both social utility expressions can be rewritten as follows:

$$
\begin{gathered}
U_{2 P G}=g\left(1-\frac{a}{8}\right)+y-2 F \\
U_{I I}=\alpha\left[g\left(1-a \frac{\alpha}{4}\right)\right]+(1-\alpha)\left[g\left(1-a \frac{1-\alpha}{4}\right)\right]+y-2 F
\end{gathered}
$$

A union with two public goods will always be preferred over two separate nations if $U_{2 P G}>U_{I I}$ for all possible parameter values. Rearranging the terms in the inequality $U_{2 P G}>U_{I I}$ gives the following inequality:

$$
\frac{1}{2} \alpha^{2}-\frac{1}{2} \alpha+\frac{1}{8}>0
$$

Since this inequality always holds, a union with two public goods is always better than two separate nations.

To determine the social optima we thus have to choose between a union with two public goods and a union with a single public good. If the costs of the public good are high, i.e. if $F$ is big, then it is socially optimal to have one public good. The following proposition summarizes these considerations.

Proposition 4.1. If $F>g a / 8$ then a union with one public good will be the social optimum and if $F<g a / 8$ then a union with two public goods will be the social optimum.

Proof: In the social optimum the sum of all individual utilities is maximized. If it is optimal to have a union with two public goods, then it will be socially optimal to choose the location of the public goods and the tax level to maximize the aggregate payoff $U_{2 P G}$ to all individuals in a union with two public goods:

$$
U_{2 P G}=\int_{0}^{1} U_{2 P G}(i) d i=g\left(1-a E\left(d_{i} \mid l\right)\right)+y-E(t)
$$

where $E\left(d_{i} \mid l\right)$ and $E(t)$ are, respectively, the average distance to the public good closest to individual $i$ given the locations of the two public goods and $E(t)$ the lump sum tax level in the nation. In order to minimize $E\left(d_{i}\right)$ it is socially optimal to locate the two public goods at $1 / 4$ and $3 / 4$. $E\left(d_{i} \mid l\right)$ will then be $1 / 8$. Since there are two types of public goods, $E(t)$ will be $2 F$. 
If it is optimal to have a union with two public goods, then it will be socially optimal to choose the location of the public goods and the tax level to maximize the aggregate payoff $U_{1 P G}$ to all individuals in a union with two public goods:

$$
U_{1 P G}=\int_{0}^{1} U_{1 P G}(i) d i=g\left(1-a E\left(d_{i} \mid l\right)\right)+y-E(t)
$$

where $E\left(d_{i} \mid l\right)$ and $E(t)$ are, respectively, the average distance given the location of the public good and the lump sum tax level in the nation. In order to minimize $E\left(d_{i}\right)$ it is socially optimal to locate the two public goods at $1 / 2 . E\left(d_{i} \mid l\right)$ will then be $1 / 4$. Since there is one type of the public good, $E(t)$ will be $F$.

Hence, both social utility expressions can be rewritten as follows:

$$
\begin{gathered}
U_{1 P G}=g\left(1-\frac{a}{4}\right)+y-F \\
U_{2 P G}=g\left(1-\frac{a}{8}\right)+y-2 F
\end{gathered}
$$

Comparing the total utilities under unification and separation determines the choice for either one or two public goods in a union. It is better to have one public good if and only if $U_{1 P G}>U_{2 P G}$ :

$$
U_{1 P G}=g\left(1-\frac{a}{4}\right)+y-F>g\left(1-\frac{a}{8}\right)+y-2 F=U_{2 P G}
$$

After rearranging terms, we find that a union with one public good is the social optimum if $F>g a / 8$

\section{Comparison}

Majority voting and social optimum compared: A comparison of the outcomes under majority voting and the social optima reveals:

Proposition 5.1. (i) If $F<g a / 8$ then a union with two public goods is socially optimal for all $\alpha \in[0,1 / 2]$ but a union with two public goods obtains for all $\alpha \in[0,4 \mathrm{~F} / \mathrm{ga}]$ and separation obtains under majority voting for all $\alpha \in$ $[4 F / g a, 1 / 2]$, (ii) If $g a / 8<F<g a / 4$ then a union with one public good is socially optimal for all $\alpha \in[0,1 / 2]$ but a union with two public goods obtains for all $\alpha \in[1-4 F / g a, 1 / 2]$ and separation obtains under majority voting for all $\alpha \in[1-4 F / g a, 1 / 2]$, (iii) If ga/4<F<ga/2 then a union with one public good 
is socially optimal for all $\alpha \in[0,1 / 2]$ but separation obtains under majority voting for all $\alpha \in[0,1-2 F / g a]$, and (iv) If $F>$ ga/2 then a union with one public good is socially optimal as well as the majority voting outcome for all $\alpha \in[0,1 / 2]$.

These results are illustrated in Figures 2. ${ }^{8}$ One of the main findings of the above result is that there exist excessive incentives for the provision of public goods. For different values of $F$, there are also excessive incentives for separation, which are partly due to the excessive incentives for public good provision. The excessive incentives for public good provision appear most distinctly for $g a / 8<F<g a / 4$ and small values of $\alpha$, while the excessive incentives for separation appear most distinctly for $F<g a / 8$ and relatively large values of $\alpha$. I now elaborate on the sources of this inefficiency.

The excessive provision of public goods arise out of the way the costs and benefits of the public goods are distributed. In a union the costs of an additional public good are $F$ which are borne equally by the individuals in the union because of the lump-sum taxation system. On the other hand, the benefits of the additional public good of an individual depend on the location of the individuals. The individuals located in the center of the union will lose most from the second public good in the union and the two groups of individuals located at both extremes gain the most. The aggregate increase in the payoff of these individuals (located towards the corners), however, is less than the decrease in the payoff of the individuals located in the center of the region. In the case of separation the individuals located close to the boundary between the two regions will lose the most and again the individuals located to the corners will gain the most.

\section{Concluding remarks}

The analysis of this model yields us two principle insights. Firstly, the large region is less keen on unification as compared to the small region. This result is due to the fact that the tax advantages from union are increasing and (strictly) convex in the size of the other region, while the political costs are linear. Thus a

\footnotetext{
${ }^{8}$ Note that $F<g a / 8$ implies that $4 F / g a<1-4 F / g a$, that $F>g a / 4$ implies $1-2 F / g a<$ $2 F / g a$ and that $F>g a / 2$ implies that $2 F / g a>1$ and $1-2 F / g a<0$ and thus $1-2 F / g a<$ $2 F / g a)$.
} 
union with a very small region fails to generate adequate tax advantages for the large region for a certain class of parameters. In the large region the incentives for unification are larger when the population in the large region is not uniformly distributed but concentrated and when the political influence of the small region in a union is smaller. Secondly, I find that the outcomes under majority voting typically lead to too many public goods provided as compared to what is socially optimal. This is due to the fact that whereas the tax advantages of having one public good are shared evenly by voters in a region, the political costs are unevenly distributed and this generates externalities which lead to inefficient outcomes. These incentives for public good provision were so far ignored in the related literature.

There are several directions in which the model can be extended. First, the analysis presented in this paper makes a step to vary the amount of public goods provided by allowing for the provision of two types of public goods in a union. A genuine variable amount of the public goods, however, will provide more profound insights into how the incentives for unification, for separation and for public good provision are related. Second, the role of decentralized public good provision -and connected, the spillover effects of public goods provision- deserves a more thorough study. Third, one can examine the robustness of the results with respect to a variety of voting rules. Fourth, I did not take into account the transfers a government can make. These transfers can be inter-individual or inter-regional and obviously have an effect on the incentives for unification. ${ }^{9}$ Another dimension of the robustness question is how decisions on unification and separation are affected by (the threat of) violence. There may be groups of persons who are unhappy with the voting outcome and they may use violent means to have their way.

\section{References}

[1] Alesina, A. and E. Spolaore, 1997, On the number and size of nations, Quarterly Journal of Economics, November, pp.1027-1056.

\footnotetext{
${ }^{9}$ Bolton and Roland (1996), Dixit and Londregan (1998), Lockwood (2002) and Lülfesmann (2002) also study the role of transfers.
} 
[2] Alesina, A. and E. Spolaore, 2003, The size of nations, The MIT Press, Cambridge, MA.

[3] Alesina, A., E. Spolaore and R. Wacziarg, 2000, Economic integration and and political disintegration, American Economic Review, 90, 5, pp.12761296.

[4] Alesina, A., Wacziarg R., 2000, Openness, country size and government, Journal of Public Economics, 69, pp.305-321.

[5] Austin, D. A., 1993, Coordinated action in local public goods models: The case of secession without exclusion, mimeo, University of Texas.

[6] Benabou, R., 1993, Workings of a city: Location, education and production, Quarterly Journal of Economics, 108, pp.619-652

[7] Bewley, T. F., 1981, A critique of Tiebout's theory of local public expenditures, Econometrica 49, 3, pp.713-740.

[8] Bolton, P. and G. Roland, 1993, The break-up of nations: A political economy analysis, Quarterly Journal of Economics, 112, pp.1057-1089.

[9] Bolton, P., G. Roland and E. Spolaore, 1996, Economic theories of the breakup and integration of nations, European Economic Review, 40, pp.697-705.

[10] Dixit, A. and J. Londregan, 1996, Fiscal federalism and redistributive politics, Journal of Public Economics, 68, pp.153-180.

[11] Epple, D., Romer T., 1991, Mobility and Redistribution, Journal of Political Economy, 99(4), pp.828-858.

[12] Jehiel, P., Scotchmer P., 1995, On the right of exclusion in jurisdiction formation, mimeo, CERAS and Berkeley.

[13] Goyal, S., Staal K., 2004, The political economy of regionalism, European Economic Review, 48, pp.563-593.

[14] Lockwood, B., 2002, Distributive politics and the costs of centralization, Review of Economic Studies, 69, pp.313-337. 
[15] Lülfesmann, C., 2002, Central governance or subsidiarity: A property-rights approach to federalism, European Economic Review, 46, pp.1379-1397.

[16] Oates, W.E., 1972, Fiscal Federalism, Harcourt Brace Jovanovich, New York.

[17] Persson, T., Tabellini G., 2000, Political Economics - Explaning Economic Policy, MIT Press: Cambridge.

[18] Rubinfeld, D. L., 1987, The economics of the local public sector, in: A. J. Auerbach and M. Feldstein, eds., Handbook of public economics, Vol. 2, North-Holland, Amsterdam.

[19] Scotchmer, S., 1996, Public Goods and the invisible hand, in: J. Quigley and E. Smolensky, eds., Modern public Finance, Harvard University Press, Cambridge, MA.

[20] Stahl, K., Varaiya P., 1983, Local collective goods: A critical re-examination of the Tiebout model, in: J. F. Thisse and H. G. Zoller. eds., Locational analysis of public facilities. North-Holland, Amsterdam.

[21] Tiebout, C., 1956, A pure theory of local expenditure, Journal of Political Economy, 64, pp.416-424.

[22] Wildasin, D., 1988, Nash equilibria in models of fiscal competition, Journal of Public Economics, 35, pp.229-240. 